\title{
Making Sense of Things: Constructing Aesthetic Experience in Museum Gardens and Galleries
}

\author{
${ }^{*}$ Gemma Mangione, Northwestern University
}

\begin{abstract}
Studies of museum behaviour in sociology often examine how external environments shape organizational practice. Through an ethnographic study, this article considers programmes for visitors with disabilities at a major metropolitan art museum and botanical garden to ask how 'sensory conventions' vary across museums, and with what effects. I trace how museum staff construct the aesthetic experience of art and nature differently to shape how visitors use their senses, and which senses they use, when interacting with museum collections. Examining aesthetic meanings across different kinds of museums reveals these institutions' differing local cultures and how such cultures affect visitor experience. In particular, aesthetic practices across museums facilitate varying opportunities for perception, and interactions that may privilege particular embodied capacities.
\end{abstract}

Key words: art museums; botanical gardens; aesthetics; senses; disability

\section{Introduction}

Conventional wisdom dictates that in museums we look, but do not touch. But how is this convention negotiated and maintained? I consider this question through an ethnographic study of visitor experience in a major metropolitan art museum, in which the opportunity to touch artworks is proscribed, and a major metropolitan botanical garden, wherein touching the plants is possible. In comparing how people come to use their senses across the gardens and galleries, I illustrate how museum staff differently construct the aesthetic experiences of both art and nature to structure visitors' interactions with museum collections.

On the one hand, the explanation is an easy one. Cultural artefacts are indeed, as McDonnell (2010) has pithily noted, 'objects:' their social life cannot be neatly separated from their material one. The physical degradation of museum collections must be carefully controlled in order to preserve their intelligibility as meaningful, culturally valuable things of this world (see Domínguez Rubio 2014). Visitors' repeated handling of collections can threaten this effort, and does so differently for a Picasso than for a petunia, not least because a painting is materially different than a flower. To offer a more complete explanation, this paper examines the forms of sensory interactions museum staff innovate for people with disabilities, visitors for whom the modal visual practice of museum-going is often most restrictive. In so doing, I show how the sensory conventions of museums are bound both by the material properties of things and our cultural understandings of them, and particularly our aesthetic understandings. Attending to the construction of aesthetics across the domains of art and nature reveals the different internal cultures of museums, and how these can significantly shape the kinds of visitor experience that are possible.

\section{Aesthetics and Museums: Theorizing the Particularity of Practice}

Part of the challenge sociologists face in explaining how interactions vary across museums stems from how we study them. As Rowland and Rojas (2006) have argued in a thorough review, sociological analyses of museums tend to theorize them as organizations highly influenced by their institutional environment, highlighting how industry standards, economic and political 
factors, and interactions with outsiders in the broader art world structure organizational practice. In focusing on external conditions, this work explains how museums exist in cultural 'worlds,' abiding by shared and relatively stable 'conventions' (Becker [1982] 2008); or in fields, adopting similar strategies over time in pursuit of legitimate practice (DiMaggio and Powell 1983; Powell and DiMaggio 1991). Despite the significant insights offered by these literatures, they tend to say less about how people 'inhabiting' different types of museums interpret and respond to institutional norms (Hallett and Ventresca 2006), or how this process may vary within the diverse category of museums. ${ }^{1}$

In what follows, I investigate how museum staff facilitate visitors' sensory interactions with the collections of The Metropolitan Museum of Art, New York (Met), and the Chicago Botanic Garden (CBG), in Glencoe, Illinois, approximately 30 miles from downtown Chicago. In so doing, I aim to open the 'black box' (Whitley 1970) of museum practice to explain how conventions of museum going - often assumedly timeless, yet quintessentially modern - vary across museums, and with what effects. ${ }^{2}$ Examining how people negotiate the 'look, don't touch' rule for visitors with disabilities reveals how museum artefacts enable different types of sensory encounters (a rose smells; a Rembrandt does not). However, I find such material affordances shape the field of possibilities while not limiting them entirely. Tracing how staff organize multi-sensory experiences of art and nature around shared understandings - interpretive aesthetics in the galleries, and unmediated aesthetic beauty in the gardens - makes this plain. By illuminating the interplay of materiality and agency, ethnographic study ultimately reveals how museum conventions are made practically - but differently - across contexts.

This paper makes two arguments. The first is ostensibly simple: one type of museum is not like another. In elaborating this, I am indebted to formative ethnographic research in science and technology studies that foregrounded the material contingencies of professional work (Knorr-Cetina 1981; Latour and Woolgar [1979] 1986; Lynch 1985) to reveal how scientific knowledge is not only structured by institutional settings, but also results from coordinated activity negotiated between people and things, embedded within particular environments (KnorrCetina 1983). This 'practice turn' further extended research foregrounding the disunity of a scientific field commonly understood to be integrated and autonomous: suggesting, as Karin Knorr Cetina (1999: 8) has argued, that scientific disciplines may best be conceptualized as distinct 'epistemic cultures' in which knowledge is practiced 'within structures, processes, and environments that make up specific epistemic settings'. ${ }^{3}$ Comparative ethnographic analysis foregrounds that museums similarly function as cultures organized around particular object domains. Borrowing from Thomas Gieryn's (2000: 465) formulation of place, it shows these organizations have a material form of physical 'stuff' that is infused with meaning and value, each 'flexible in the hands of different people or cultures, malleable over time, and inevitably contested'.

My second argument emerges from my first. Aesthetic meanings, as they pertain to museums, are locally determined, and as a result, sociological research on museums should pay greater attention to the particularities of practice. Indeed, aesthetics offers an exemplary site through which to consider both how the meanings produced in different museums vary based on the 'stuff' available and the attendant implications. As Gordon Fyfe (2006: 37-9) has noted, given that aesthetic appreciation of high culture is stratified by class (Bourdieu 1984; Bourdieu and Darbel [1969] 1991), sociologists examining museums from an institutional perspective have tended to focus on the social contexts perpetuating social inequalities, rather than how such conditions are interpreted. Fyfe (2006) further highlights the centrality of art museums to this formulation of museums' 'dominant ideology,' suggesting that differences between institutions necessitate 'bring[ing] the museum itself into the analytical frame'. My analysis shows not only how aesthetic understandings vary across museums - thereby foregrounding the centrality of context for sociological analysis - but also how people challenge, negotiate, and elaborate the ostensibly fixed or 'dominant' conventions associated with such understandings. Tending to the diverse internal cultures of museums through comparative ethnography ultimately illuminates how the aesthetic experiences within them are produced 'by specific practices in given conditions' (Wolff [1983] 1993): 105; see also 85-104). ${ }^{4}$

In what follows, I show how museum staff organize aesthetic experience and elaborate it through interactions that in turn structure sensory perception. The first section, 'Behaviour 
Settings and Aesthetic Seeing,' describes the Met and CBG's 'sensory conventions,' which explain how visitors use their senses - and which ones they get to use - in a given museum context. ${ }^{5}$ This discussion provides a foundation for studying the adaptations museum staff develop for visitors with disabilities. I show that while each institution constructs a visual aesthetic practice, those in the garden frame theirs as engendering socially-unmediated perceptions of beauty while those in the galleries foreground close looking as central to interpretation. In the second section, 'Making Sense,' I illustrate how first, horticultural therapists at the CBG, and second, access educators at the Met, work with visitors with disabilities to construct aesthetic experiences that engage the non-visual senses, and particularly touch.

\section{Data and Methods}

Data for this article comes from a larger ethnographic study of American art museums and botanical gardens accredited by the American Alliance of Museums (see n.1). In particular, I draw upon participant-observation of the Met and CBG's programmes for visitors with disabilities conducted between 2010 and 2014. To trace how these specific initiatives relate to their broader institutional context, I also draw on observations of a sample of programmes developed for other audiences and a total of 50 interviews with museum staff: 31 at the Met and 19 at the CBG. I use pseudonyms for research participants and have changed identifying information, excepting one key informant in each site who agreed to be identified.

Loosely structured by developmental learning theory, museum education departments tend to be organized by audience, including, for example: students; teens; adults; and intergenerational units like families. Both the Met and CBG have dedicated programme offerings for visitors with disabilities, thus providing apposite case studies for examining the sensory conventions of museums. ${ }^{6}$ Indeed, it is for this particular visitor public that opportunities for multi-sensory museological engagement are more typical and thus analytically explicit. Such programmes serve, but are not limited to, people who are blind or have visual impairments, as well as people with varying language abilities, for whom the practice of facilitating observationbased dialogue is often most in need of adaptation. Concentrating on staff who lead programmes focuses empirical attention on those professionals tasked with engaging the institution's diverse publics and making accessible its collections (Mangione 2013; Zolberg 1992).

Located within the Garden's Education and Community Programs, the CBG's horticultural therapy programme primarily serves groups of visitors from social service agencies and community centres. During my fieldwork, I had the opportunity to observe gardening workshops for: those in stroke rehabilitation groups; residential communities for the blind and people with visual impairments; schools serving children on the autism spectrum; people with dementia; veterans; and individuals recovering from substance abuse. Professional care partners typically scheduled these programmes and participated in them alongside visitors. While the Met's accessibility or 'access' programme serves many of these same populations in providing by-request group programmes for organizations, they also offer monthly, more specialized initiatives for visitors with particular disabilities. These include tours and art-making programmes (or combined programmes) for people with visual impairments; who are deaf and hard-of-hearing; with developmental disabilities, including those on the autism spectrum, who attend with their families and friends; and for those with dementia, attending with professional or family care partners. While each institution offers off-site programmes, this paper considers those offered at the museum itself to focus analysis on how staff facilitate visitors' interactions with collection objects.

During programmes, I participated as both an observer and volunteer, arriving early and staying late to help with set-up, check-in, and clean-up as needed. This familiarized me with logistics of programme execution and provided me access to summative reflections. While observing, I regularly wrote fieldnotes in both sites. In educational settings like museums, this is not unusual, particularly given that other staff members, students, volunteers, or consulting professionals often follow programmes for evaluation and training purposes. When participants asked directly about my role, I clarified that I was a graduate student.

Analysis was inductive (Glaser and Strauss 1967), and it consisted of reviewing interview transcripts and field notes and tracking patterns in ATLAS/ti, a qualitative data- 
analysis programme. I conducted interviews after a pilot period of observations in 2010 , and then following an additional six months of observation in each site, so as to directly address patterns I had observed through analysis. Delayed interviews also allowed me to identify relevant interviewees in other departments - among them visitor services, curatorial, and horticultural staff members - whose work is implicated by and in turn shapes the sensory conventions of their institutions. Additional informal conversations with museum staff and participants were a regular part of my fieldwork and an important part of my ethnographic record.

\section{Behaviour Settings and Aesthetic Seeing}

\section{Value Constructions and Touch}

At a general level, the organizational identity of a museum confers a certain degree of symbolic value upon its objects that they may not have if located elsewhere (for example, should a passer-by come across an unidentifiable painted canvas languishing in an alley in Montmartre, they would have fewer qualms picking it up than if it was hanging on the walls of the Louvre).

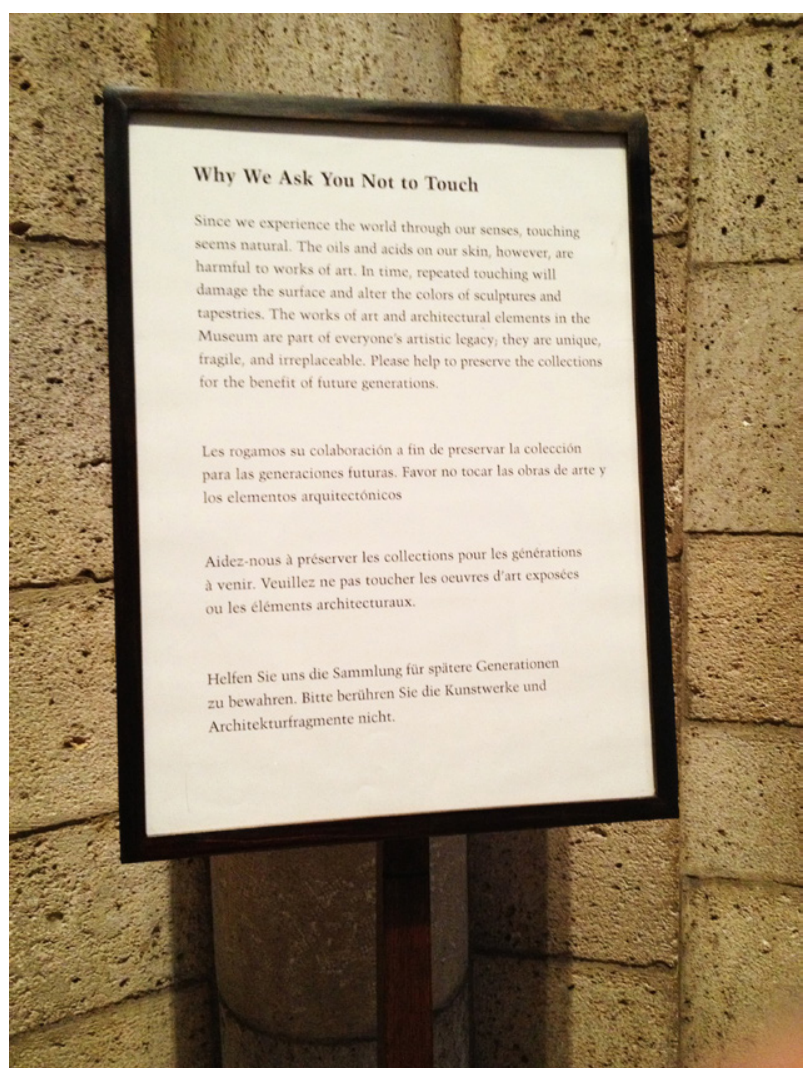

Fig. 1: 'Why we ask you not to touch'. Photograph taken by the author, September 18, 2013, at The Metropolitan Museum of Art (Cloisters), 99 Margaret Corbin Drive, New York, NY 10040, USA

paused to examine a visitor's name carved into the thick, thorn desert conservatory. It is commonplace - perhaps even romantic, when it comes to lovers' initials - to see such inscriptions in the bark of trees. But within the space of the museum, the staff member noted, 'it's plant vandalism'.

This conservationist logic offers an important starting point for understanding what is possible in terms of visitors' sensory engagement with museum collections. At the Cloisters, the satellite branch of the Met dedicated to medieval art, a sign in the main ticketing hall makes the rationale for the museum's 'hands-off' policy explicit: 'the works of art and architectural elements in the Museum are part of everyone's artistic legacy; they are unique, fragile, and irreplaceable'.

Met educators use a similar rhetoric when guiding their in-gallery programmes; when leading a school tour, one employee explained to a group of fifth-graders who had correctly identified the 'no touching' rule as the museum's most important: 'Yes, that's right. Because we want to keep things safe and clean forever, so people can keep coming back to see them'. Such emphasis on protecting collections further resonates with CBG staff members' distinction between the botanic garden and 'natural' spaces, such as a forest or park. During a professional development session for special education teachers, the facilitator education teachers, the facilitator
thorn-edged leaf of a plant in the 
However, value constructions of museum collections are ultimately informed by, but not reducible to, the organizational identity of the institution. Across these domains, differences in objects - what they're made of, how people understand them, and how people use them - matter. For example, it is unthinkable for one to imagine a visitor carving initials into an Impressionist canvas, but probable (albeit condemned) to have such etchings on a greenhouse plant. Similarly, while Pieter Bruegel the Elder painted but one of The Harvesters, a famous Flemish landscape traditionally on view in the Met's European Paintings galleries, there are more than 5,000 rose bushes in the CBG's Krasberg Rose Garden; they wither away each winter and grow back again late in the spring. ${ }^{7}$ Creativity and craft lead people to confer an additional degree of symbolic value on museum objects regardless of whether they're rendered through paint or with plants, or located in the gardens versus the galleries. Each display table in the outdoor bonsai exhibit at the CBG is wired with an alarm system to caution visitors against venturing too close to each tree's carefully curated branches. ${ }^{8}$ Similarly, beside nearly every one of the 16 different Ikebana flower arrangements in the Met's spring 2014 exhibition was a sign beside it reminding visitors 'Please don't touch'.

Sensory conventions are thus ultimately not born, but made. Rather than an immutable property of museums, they are best understood as socially constructed, as is reflected in John Falk and Lynn Dierking's (1992: 64-5) discussion of museums as 'behavior settings'. ${ }^{9}$ As they point out, museums can be classified as 'hands-on,' such as science centres and children's museums, which encourage active participation with exhibits; or 'hands-off,' such as art, history, and natural history museums, in which the public expects to find treasured, priceless objects which they must look at, but not touch.

The trouble comes when these two dimensions are blurred, and botanical gardens offer an exemplary case of such ambiguity. The environment of the CBG is far less controlled than that of the Met and thus does less to set up expectations for how visitors might 'behave' - here, sensorially engage - in the garden in comparison to galleries. As visitors pass through the Met, their footsteps echoing over marble and hardwood, the museological organization of space clearly maintains their distance from collection objects. Low silver rope barriers and glass displays separate the people from the artworks. If one leans in too closely to particularly fragile freestanding objects, alarms either human (watchful security officers) or occasionally technological (piercing, repeated, beeped warnings) sound immediately. In contrast, personnel throughout the CBG make visible the banality of plant-people interactions. They typically include the various workers in overalls and jeans clipping, pruning, propagating, and mowing along the stone and brick paths that weave through the Garden's manicured grounds. While security personnel respond to calls, travelling the grounds on golf carts, one staff member said: 'It's really hard to protect the plants,' including, she noted, on occasion from theft. ${ }^{10}$ The beds of plants and flowers at the CBG are open to the public, for people to lean in to and notably, to smell. Scents from the garden fill the air but are all the more vivid when one leans in closer for a whiff, a sensory affordance of nature less prominent in art.

\section{Art, Plants, and Aesthetics}

Smell is, further, a form of sensorial intimacy less problematic than touch, which people view as the greatest threat to museum collections. Accordingly, one context in which CBG staff members offered the clearest explication of the problems of touch, and in which they articulated a modal practice of visual engagement, was in discussing the aesthetic of the garden. Generally, this regarded how the garden looked. As one CBG horticulturalist admitted: 'It's possible to touch any plant. But you don't encourage it... otherwise you end up with a lot of trashed plants'. ${ }^{11}$ One CBG curator elaborated this to say: 'There's really no problem with people touching the plants. That doesn't really hurt the plants at all. We discourage them from picking the plants, or anything off of the plants, because that can affect the way it looks'. ${ }^{12}$

When asked to define the aesthetic of the garden with greater specificity, an array of museum professionals emphasized the import of 'beautiful' displays, a word they associated with visual experience. Their discussions of beauty spanned various dimensions of garden policy and practice, among them exhibition design. In museums, curators build collections favouring various criteria, and in our conversation, the CBG curator emphasized aesthetic 
beauty as principal among them. For example, he discussed the garden's interest in planting cultivars, a variety of plant selected for desirable and often decorative characteristics that can be sustained by propagation (among them roses, daffodils, and azaleas). Ultimately, he stated, 'because we are a display garden... we [at the CBG] tend to try to have the showiest plants'. When asked what 'showy' meant, he explained: 'Like, ornamental... we try to have these really fancy showy exhibits. That's why we have so many annuals here every year. That's why we plant thousands of tulips every spring'. Speaking with another employee in facilities, I asked him to define what he meant by aesthetics, a word I noted he had used considerably when reflecting on a successful visitor experience of the garden. 'Simply put, beauty', he responded:13

And the universality of human beings to respond to beauty in the natural world... if you narrow that down to an assembly of plant materials, and things with flowers, good colour... That's an essential part of creating an aesthetic that's beautiful... that is engaging. Think of the Rose Garden... here's this profusion in June and echo in September of beautiful roses, attractively arranged to be able to see them successfully, to walk among them, the way the paths works, and so forth.

This employee's quote underscores that the beauty of the CBG's 385 acres is in fact the product of significant intervention and design work: an effort to please the eye by 'creating' and 'arranging' a particular aesthetic experience. The script for the CBG's Bright Encounters tram tour through the garden further provides evidence for the positioning of aesthetic beauty as primarily visual by contrasting it to olfactory experience: 'Some (roses) are strongly scented, while others are appreciated strictly for their beauty'.

At the Met, in contrast,

to 'see' is not necessarily to experience pleasurable beauty from a natural object, but instead, to interpret a representation using visual evidence. Here an institutional emphasis on close looking emphasizes the opportunity to learn from, and thus gain, greater appreciation of an artwork. One way this becomes evident is in considering the informational materials accompanying Edouard Manet's Young Lady in 1866, an appropriate work for thinking about the role of senses in aesthetic representation. The text label adjacent to the painting notes

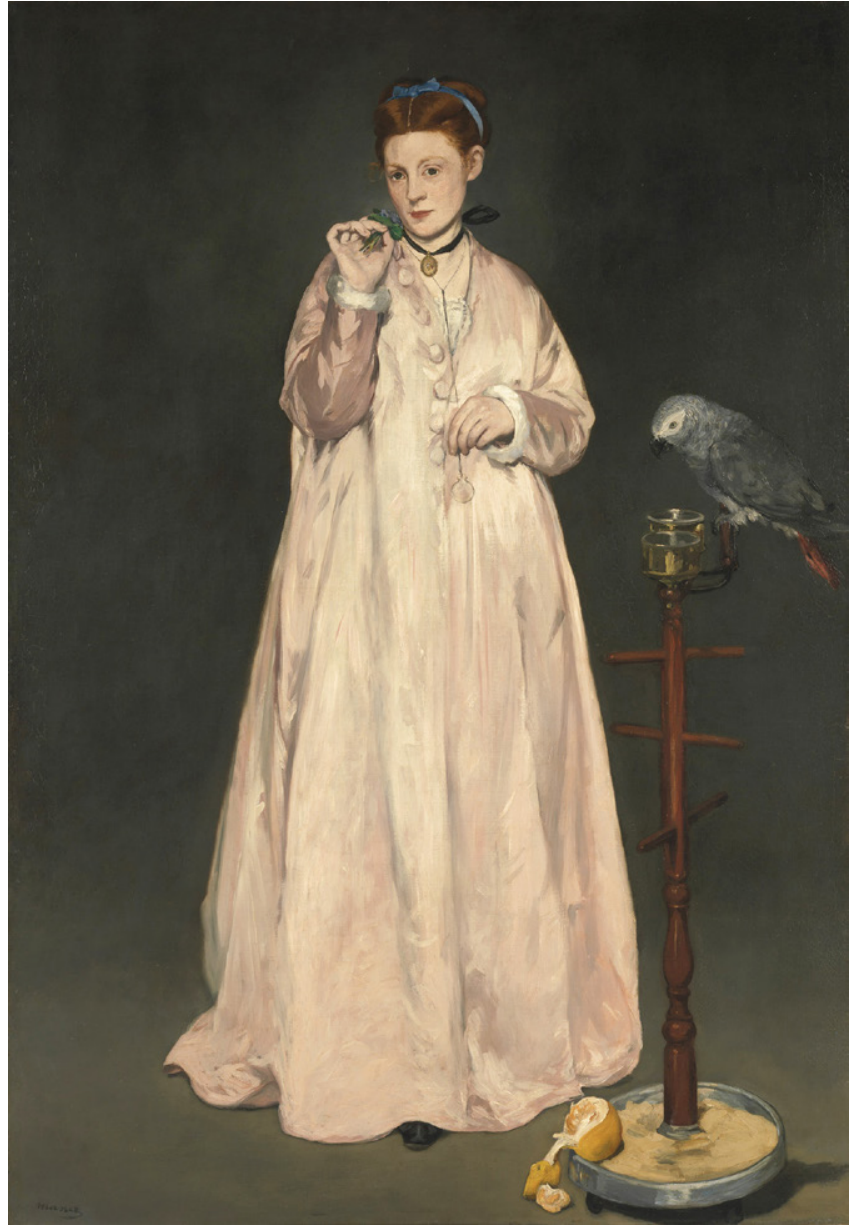

Fig. 2: Manet, Édouard. 1866. 'Young Lady in 1866'. Oil on canvas, 185.1 x $128.6 \mathrm{~cm}$. The Metropolitan Museum of Art, Gift of Erwin Davis, 1889 (89.21.3). Image @ The Metropolitan Museum of Art 


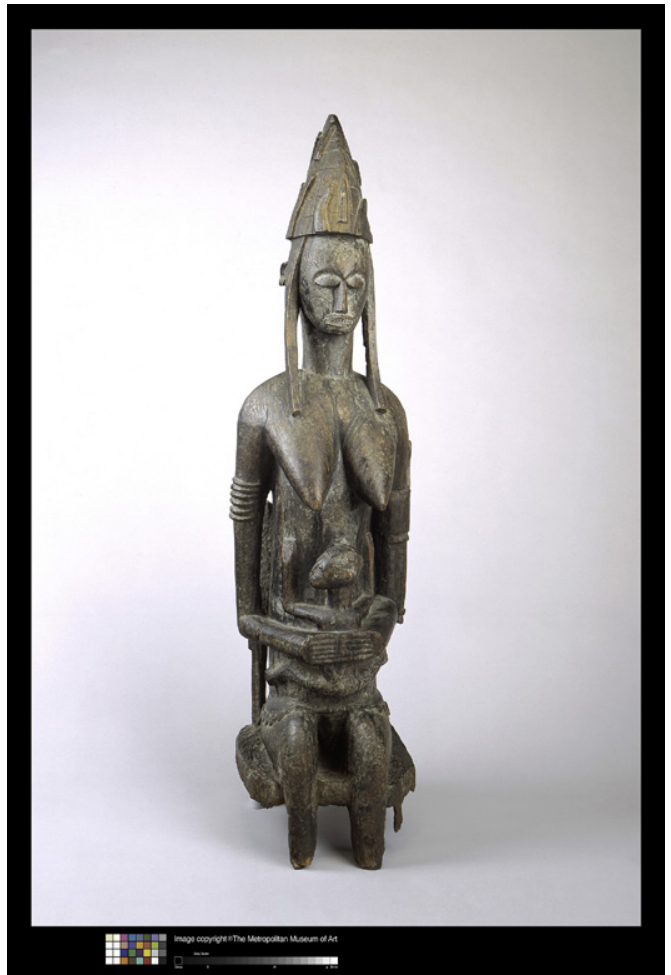

Fig. 3: Bamana peoples (Mali, Bougouni or Dioila region). 15th-20th century. 'Mother and Child'. Wood, H. $123.5 \times$ W. $36.6 \times D .36 .5 \mathrm{~cm}$. The Metropolitan Museum of Art, The Michael C. Rockefeller Memorial Collection, Bequest of Nelson A. Rockefeller, 1979 (1979.206.121). Image (C) The Metropolitan Museum of Art

elements in the artwork - the parrot, the orange, the nosegay - that support its curatorial interpretation as an allegory of the five senses.

This process of using visual perception as evidence to engage with a work of art also extends beyond the self-guided visitor. During tours of the galleries, educators regularly solicit visitors' opinions on the works in front of them through open-ended questions, then ask them to refer to visual elements of the work that support those opinions. This practice spans across audiences, including in this programme for visitors with dementia and their caregivers: ${ }^{14}$

\begin{abstract}
Harriet, seated on a stool next to the Bamana peoples' Mother and Child, asks the group of twelve people in front of her to take a moment to look at the work. One participant, Marta, sitting tall in her own stool with long dark hair flowing past her shoulders, offered that the figure appeared 'proud' and a beat later, 'strong,' prompting Harriet to repeat this back to her before asking: 'What in her suggests power, or pride, or strength?' Her posture, several people in the group agreed. Harriet then offered that she had read the work represented an 'ideal' of strength, going on to clarify that this was a sculpture that was used in an important ritual ceremony for men coming of age. These heroes were
\end{abstract} usually men, but this, unusually, was a woman. She went on to share that the effect of gravity on the woman's figure (particularly, her long, pendulous breasts) 'shows her experience,' or her age. To this, another participant, Sarah, gestured to the small child wrapped around the woman's torso, stating that the statue reminded her of a fertility goddess and perhaps her breasts were 'weighted with milk.' Harriet began to nod, immediately: 'So it's not just about her experience, but also their use.' Sarah nodded as well.

The Met's encyclopedic collections include objects ranging from the life-size Body Masks of the Asmat people of Papua New Guinea to the nineteenth-century Impressionist canvases rendering water lilies in the south of France to Ellsworth Kelly's $7 \times 4 \mathrm{ft}$ series of monochromatic painted panels. This diversity, coupled with the rise in contemporary art forms that challenge pre-conceived ideas about what art is or should look like, offers a counterpoint to an aesthetics aimed at engendering unmediated judgments of beauty. To this point, one Met educator, reflecting on how she selects objects for discussion on her tours, outwardly rejected the idea that she might shy away from more abstract, less figurative works. While acknowledging these might be more challenging to decipher, she emphasized her role in constructing aesthetic experience was to facilitate interpretation, rather than limit content: ${ }^{15}$ 
[To say] 'oh this kind of artwork is better for this audience, or another' that's limiting... I don't want to underestimate my audience... I have the highest standard for giving them what I consider to be the most aesthetically high level of experience.

In another example foregrounding how 'beauty' is used differently across the gardens and galleries, a Met curator noted that a number of works in the museum's collections are archaeological. A museum's artwork may thus not be 'just about the beauty' in the conventional sense of a 'masterpiece,' she explained, but rather, about historical significance. As an example, she cited an ancient wooden hammer in the Egyptian collections. ${ }^{16}$

Across the gardens and galleries, staff construct aesthetic perception as visual. However, at the CBG, aesthetics is constructed as beauty, used nearly interchangeably with pleasurable sensation. In contrast, Met staff construct visitors' aesthetic experience as interpretive. Importantly - and as the above educator's quote indicates - this binary reflects other perceived differences between art and nature shaping the practices of these institutions, foregrounding how staff members respond to understandings of art and nature created beyond museum walls. For Met educators particularly, beauty was a laden term they rarely offered in discussing artworks on programmes, choosing instead to empower visitors' assessments of objects and solicit their contributions.${ }^{17}$ As one educator acknowledged when speaking about adult audiences specifically, people 'see the artwork in this museum and they have a lot more baggage connected to all of it', an opinion seconded in a separate conversation about student visitors with her colleague in school programmes. ${ }^{18}$ Overall, these perceptual constructions reveal how museum staff presume a greater democratic capacity for aesthetic appreciation of nature as compared to art.

\section{Making Sense}

Comparing the organization of sight across the gardens and galleries reveals how people 'make sense' differently in museums. In the following section, I examine how museum staff extend definitions of aesthetics as beauty and interpretation beyond visual perception when facilitating various sensory experiences for visitors with disabilities.

\section{Aesthetic Beauty: In The Gardens}

The CBG constructed the Buehler Enabling Garden as an update to the Garden for the Learning Disabled, a space founded and financially organized in the mid-1970s by Elsie Sutter, a longtime member of the Chicago Horticultural Society. ${ }^{19}$ Buehler, constructed in 1997 on the main campus, included and expanded its predecessor's accessible technologies to facilitate gardening opportunities for visitors with various forms of disability. Among these features are raised beds to minimize the need for bending, stooping, or reaching, and hanging baskets that can be lowered to a gardener's working height, or to that of a visitor in a wheelchair. The garden also has a small outdoor pavilion where it regularly hosts groups - visitors and staff - from social service agencies, facilities, clubs, and schools for gardening workshops or volunteer work.

During scheduled workshops, the group leader typically guides programme participants through the garden shortly after their arrival, encouraging them to explore using all of their senses. Visitors can feel the hairy, velvety softness of the lamb's ear adjacent to the garden's raised pools, or staff may encourage them to smell the lavender, growing tall and thick out of the rich brown dirt in its red-brick ground planters. Buehler's collections further vary by season. In the summer, for example, visitors might touch the raspy, wispy stalk of the feathery red celosia plant, sticking out of the large terracotta pots in the container courts. The interactional moment is the moment of sensory engagement itself - of bodies meeting plants - unmediated other than the programme leader's directing attention to a given plant and providing facts to enrich the encounter. Following the tour, volunteers and staff assist participants with a gardening activity that often draws on the plants within Buehler itself. In one common propagation activity, visitors select and clip one of three types of coleus plants. They can then sit in the outdoor classroom pavilion to pot the coleus - dipping their hands into soil piled into black plastic trays; watering it, and then balling it up into cool, earthy clumps to test its consistency; digging for crunchy particles of Perlite - before taking it home. 


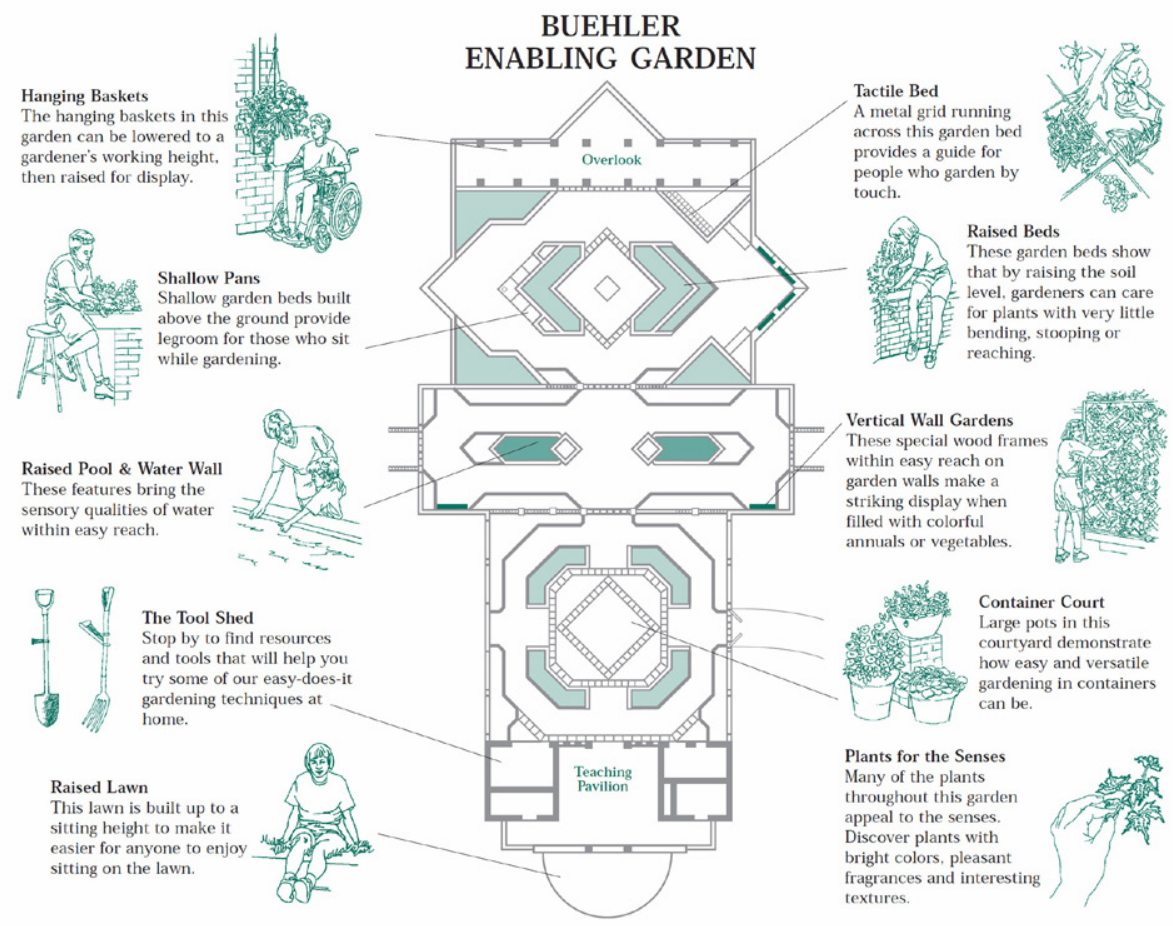

Fig. 4: Schematic layout, Buehler Enabling Garden. Garden guide brochure available online. https://www.chicagobotanic.org/downloads/gardenguides/EnablingGuide.pdf, accessed 10 March 2016. (c) Chicago Botanic Garden

One hot June day early in my fieldwork, I stood in Buehler with Alicia Green, one of the CBG's horticultural therapists and coordinator of the Enabling Garden. Noting the variety of sensory possibilities across Buehler - chocolate mint-scented geraniums, edible nasturtiums - I asked Alicia how she went about selecting the plants installed in this particular garden. In response, she explained her perceived contrast between the aesthetic, the CBG's (visual) criteria; and the 'functional' (her criteria). In the latter category, she included what she termed 'sensory' plants with 'otherwise programmatic' use - such as herbs that can be harvested and used in dips - and added these were particularly important for the hands-on gardening workshops she led in Buehler. As she clarified in later conversation: 'It has to be a sensory plant in order to be in this garden... a balance and a mixture of all the senses, stuff that smells good, tastes good, looks good, and feels good'. In contrast, she noted, 'other areas' of the garden favor plants that are 'botanically interesting or beautiful'. ${ }^{20}$

While it is easy enough to understand the functional value of herbs (culinary), or of coleus (which propagates easily), one is left to consider the 'function' of a plant that 'smells good, tastes good, looks good, and feels good'. Notably, while Alicia places sensory experience at odds with the aesthetic of the CBG, her selection of plant materials in fact extends the definition of aesthetics offered by the staff member in facilities: 'the universality' of people's response to beauty. Through her curatorial practices, however, she suggests perceptions of nature's pleasing beauty do not emerge solely from visual experience.

Her programme facilitation sheds light on the implications of this effort. For example, during one special tour of the CBG's English Walled Garden led for a group of blind and partially-sighted visitors, sighted guides accompanied participants throughout the garden. They facilitated tactile exploration of the branches of the English Walled Garden's beech tree; the moss between the hand-pressed bricks of its stone walls; and its regional flora. I spent much 
of my time with a volunteer staff guide, Elizabeth, and a partially-sighted Latina woman, Anna. At a discussion of the ornamental onion - 'it can grow to the size of a basketball,' Elizabeth explained - Anna, with Elizabeth's assistance, leaned forward and palmed the plant. Running her hands over its feathery white blossoms, she proclaimed after a moment: 'Pretty. Beautiful'. This assessment resonated with a comment Alicia herself made during that first conversation in June: 'Something that is not very pretty to us may be very pretty to (visitors with visual impairments). Because they see it with their fingers'.

The broader impact of CBG staff members' attention to nature's multi-sensory pleasures can also be seen in the garden adjacent to Buehler. While the Sensory Garden was originally 'specifically designed for the partially-sighted,' the CBG - collaborating with The Hadley School for the Blind in Winnetka, Illinois - decided to broaden its focus. As Dr Robert Winn, a special education administrator and then-director of the Hadley School who was himself blind, wrote in prepared remarks for a CBG committee meeting: ${ }^{21}$

....in so many areas in the aesthetic world of the arts, plants - you are not allowed to touch. You're only allowed to see... what happens in early childhood, and you've seen this in stores where the mother slaps the hand of the child and says 'do not touch.' If a child picks up a vegetable in the grocery store and starts smelling, you slap the hand - 'do not smell.' You're only supposed to look at things. I think your Sensory Garden offers an opportunity for many adults as well as children to gain that aspect of appreciation which in our society we tend to train out those people at a very young age.

In the present day, interpretive materials within the Sensory Garden and available online emphasize inclusion while preserving the rhetoric of a beautiful, pleasurable garden experience that spans beyond the visual. The current guide to the garden underscores the CBG's modal visual aesthetic in stating (emphasis mine):

Even though we experience gardens through our senses, many of us limit our enjoyment to what we see. The William T. Bacon Sensory Garden is designed to be a beautiful garden that appeals to more than just the eyes. It is a great place to awaken your other senses and experience beauty in a whole new way.

Throughout the garden itself, descriptive signs discuss both the value of touch and even provide reasons to do it. In the designated 'Touch Garden,' a sign acknowledges that 'one of the most enjoyable ways to experience a garden is through your sense of touch'. Another smaller, adjacent sign, discussing the 'aroma of leaves,' notes that in some plants, fragrance is found in the leaves and stems rather than the flowers, thereby not only encouraging, but necessitating, touch: 'The leaves of many plants need to be rubbed or crushed to give off their full aroma. Gently rub the leaves of the plants in order to discover their unusual scents'.

\section{Aesthetics and Interpretation: In the Galleries}

Given the constraints on interactions with collections at the Met, it follows that opportunities for touch are restricted to particular publics. Two possibilities exist for direct tactile engagement. First, people may schedule an appointment to explore the museum's touch collection, an assemblage of replicas, models, and original works of art contributed by the conservation and curatorial departments for the purposes of educational programming. Second, they may tour on their own or with a guide a select group of objects within the museum itself, most regularly a designated group of ancient Egyptian sculptures. Programmes with the touch collection take place in classrooms in the Education Center, located outside of the main galleries, where participants sit at tables covered by white foam runners. They are regularly scheduled for groups of visitors with dementia and their care partners, or by appointment with blind and partially-sighted visitors. Touch opportunities in the galleries proper are entirely restricted to the latter, with signage emphasizing the restrictions.

Within these constraints, Met access educators endeavour to extend their existing aesthetic discourse from the visual to other senses. If one is taught to see within the art museum as a way to better interpret an artwork's meaning, these staff members construct the non-visual 
senses as having analogous interpretive potential: as offering an important way of 'knowing' an object. For example, consider how Rebecca McGinnis (Senior Museum Educator in Met access) explained the difference between sight and touch at one national workshop led for a group of professionals in the field of arts and disability:

We think about (touch) mostly for visitors with vision loss, and think of it a little bit sloppily as this is the equivalent of seeing, or a stand-in, which it isn't... With sight we get certain types of information about an object: overall form, shape, spatial orientation. A lot of information is really visual-spatial information. Whereas touch is the substance, the physicality of the object - texture, hardness, temperature, volume, weight, contour. You can't tell the temperature of an object by looking at it. Touch offers you something vision can't give you... because tactile perception differs from visual perception.

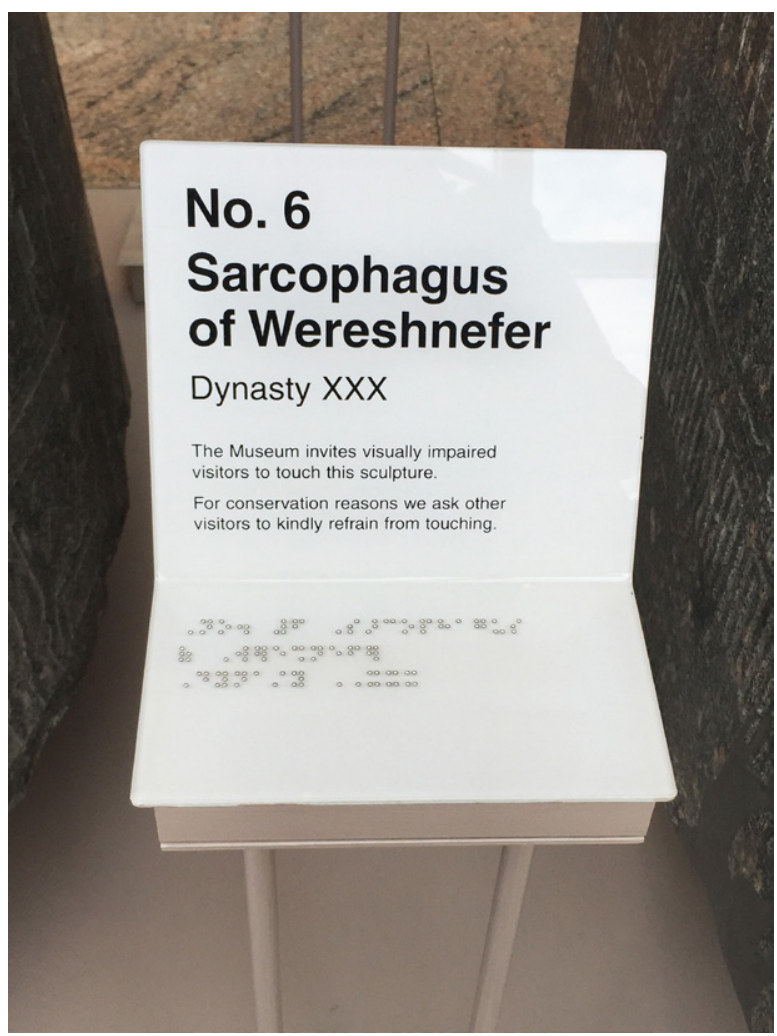

Fig. 5: Photograph taken by the author, January 2, 2016, at The Metropolitan Museum of Art, 1000 Fifth Avenue, New York, NY 10028, USA Building on these distinctions among senses, Met access educators ultimately advocate for the interpretive potential of multi-sensory experience by positioning 'multi-modal learning' as a distinct teaching modality. Notably, Met educators working with a variety of audiences expressed familiarity with this approach, defined by one senior staff educator as 'structuring experience in a wide variety of ways and through different means of accessing through the body'. ${ }^{22}$ In programmes for access audiences specifically, multi-modal learning focuses on strategies for sensory engagement that could be incorporated into programmes for all audiences.

Two were particularly common throughout my fieldwork. The first involved the use of 


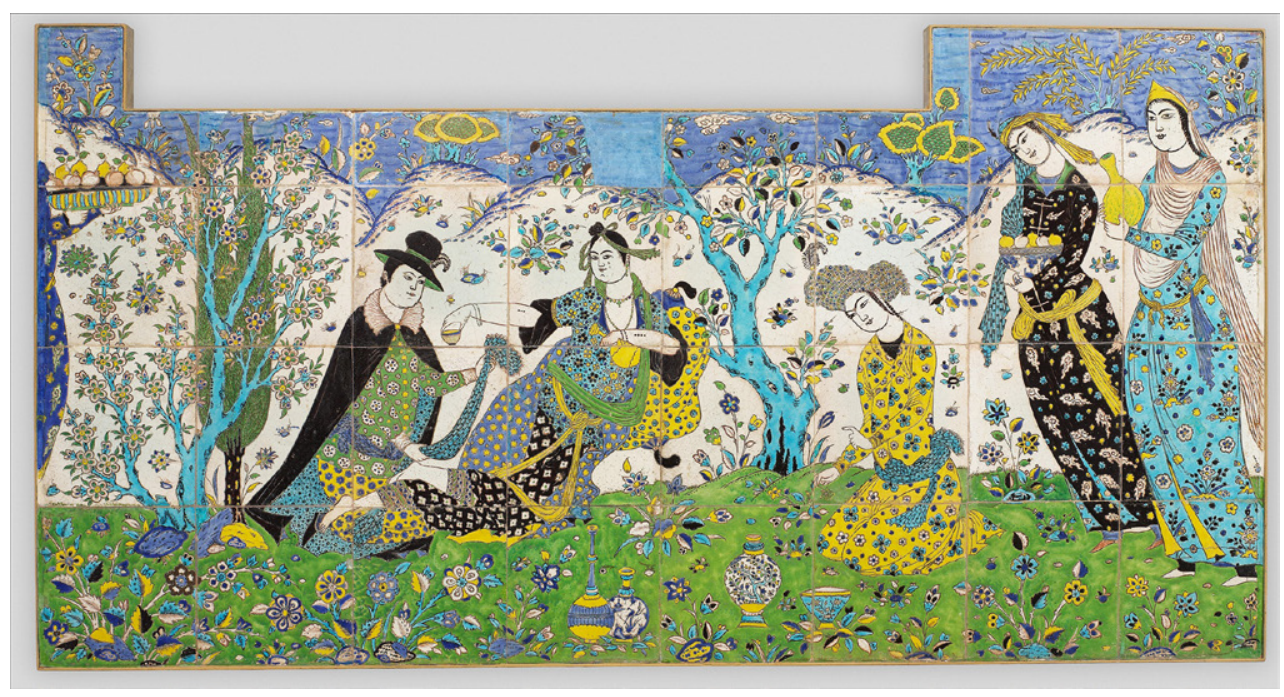

Fig. 6: Tile panel (Iran). 1640-50. Stonepaste; painted and polychrome glazed (cuerda seca technique). Panel with tabs: $H .104 .1 \mathrm{~cm} \times$ W. $188 \mathrm{~cm}$ x D. $6.4 \mathrm{~cm}$. The Metropolitan Museum of Art, Rogers Fund, 1903 (03.9c). Image (c) The Metropolitan Museum of Art

'handling materials': objects passed around and incorporated into discussions on tours. In one programme with visitors with dementia focused on an Islamic tile panel, the educator passed around a palm-sized clay tile. Cool to the touch, smooth in its glazed surface, and slightly rough on its unfinished bottom, the sample offered a non-visual contrast of scenes painted on canvas versus on clay. Shortly after, the educator brought a lemon around to each participant. After one caregiver scratched its rind to release the citrus aroma into the air, the educator asked the group if they found the smell refreshing, calling attention to the small panel details of lemons piled high on serving trays. Such materials both create intimacy with objects that must otherwise be experienced from a distance and provide additional information about them. In conceiving of artworks as a narrated scene - here, focusing on the figures about to offer the lady her snacks while she languidly leaned in the garden - educators can render dimensions of the tableaux otherwise only represented visually.

Second, Met access educators emphasize the interpretive potential of the senses by broadening the category beyond sensory experience in everyday parlance. So, while touch, taste, smell, sound, and sight provide information about the world external to us (exteroceptive), interoceptive senses, in contrast, provide information about the internal world of the human body, including among others movement (kinesthesia) and proprioception (the positioning of the body in a given space) (Vannini et al. 2012: 6). Multi-modal learning as Met staff embrace it thus includes both exteroceptive and interoceptive sensory approaches. In this way, they make use of one of the primary affordances of the art experience, particularly those opportunities offered when one encounters a sculpture. As a Met curator explained to me, nodding to a visitor imitating the arching pose of Augustus Saint-Gaudens's bronzed Diana: ${ }^{23}$

Looking at sculpture is a participatory act.... People love to pose in front of these objects, and that's a form of engagement and interaction with them. Being able to move around them, being able to get up close and appreciate... that what you see in a sculpture changes depending on your vantage point.

Educators often facilitated movement exercises - the positioning of bodies in space - to further visitors' understanding of artwork. For example, working with a group of blind and partially-sighted children and their parents in front of Auguste Rodin's The Burghers of Calais, one educator had the families work together through description and physical positioning to embody the agonized postures of the men. The educator asked the group to think about how 
the man was feeling. Offering an interpretation of embodied pain, one of the children stated: 'He has a headache!' as she stood with her hands to either side of her head, fingers spread and digging in. Later, the educator asked the children to again 'think about our bodies when we were being the sculpture. Do you think the story that happened was happy, or sad?' The

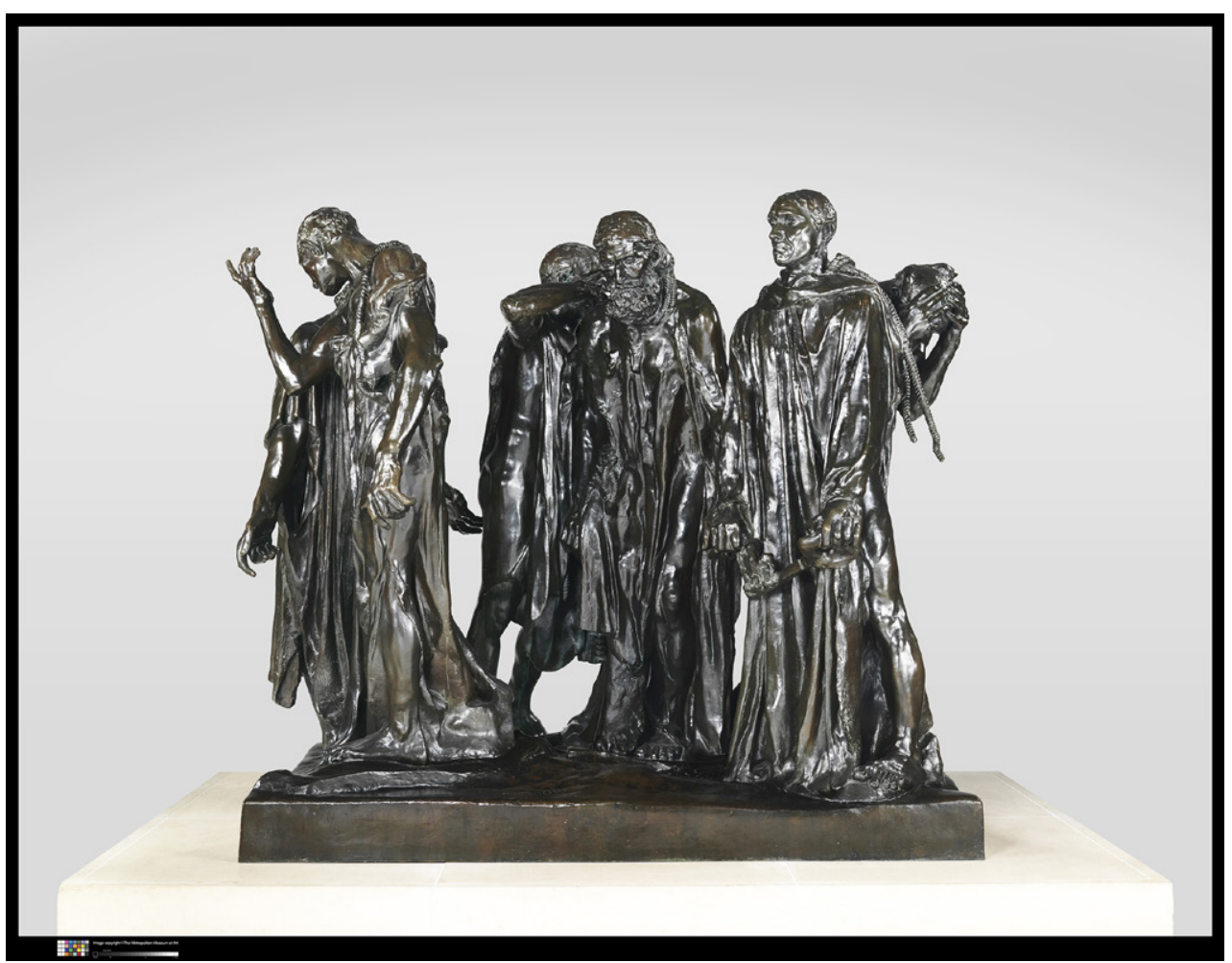

Fig. 7: Rodin, Auguste. 'The Burghers of Calais'. Bronze, H. 209.6 x W. 238.8 x D. $241.3 \mathrm{~cm}$. The Metropolitan Museum of Art, Gift of Iris and B. Gerald Cantor, 1989 (1989.407). Image () The Metropolitan Museum of Art

chorus of voices rose in response, with emphasis: 'Saaaad'.

\section{Discussion and Conclusion: On the Implications of Aesthetic Practice}

This paper has examined how sensory conventions vary across different types of museums, and with what effects. I began by showing how sociologists studying museum behaviour have tended to theorize museums as organizations that respond similarly to their external institutional environment. An ethnographic perspective, I suggest, foregrounds both the internal heterogeneity of the museum category and the content of museum practice. Comparing museum gardens and galleries reveals the local cultures of both by highlighting the differing contingencies of museum work and how these come together to impact visitor experience. In particular, botanical garden and art museum staff working with people with disabilities must negotiate the affordances of their collections to incorporate multiple senses into perceptions of nature's beauty and interpretations of art, aesthetic experiences otherwise constructed visually within their institutions.

Two implications of these findings bear note. First, theories examining how external conditions impact organizational behaviour - including those applied to museums - have done so in large part to theorize organizational change, and an ethnographic perspective can prove helpful to this endeavour. As David Howes (2014: 262) has acknowledged, the move in 
museums to 'reverse the hands-off trend' is part of these institutions' efforts to make themselves more engaging and accessible to a wider range of contemporary visitors (see also Levent and Pascual-Leone 2014). Examining aesthetic practice embedded in different local contexts illuminates the material and symbolic conditions mediating how they do so. Specifically, those in botanical gardens rely on nature's multi-sensory affordances in ways that establish both its accessibility and its 'universal' value. In contrast, staff in the art museums, and particularly those leading programmes, encounter greater constraints not only facilitating opportunities for extra-visual engagement but also managing (to paraphrase the previously quoted educator) the 'baggage' visitors bring when they come through the door.

Second, comparative study of aesthetic experience across the gardens and galleries reveals how museums make particular types of sensory knowledge possible by facilitating certain interactions while limiting others. My analysis reveals that people's construction of aesthetic experience across museums makes explicit how visitors are supposed to act in a given museum: how they are expected to use their senses - in essence, to 'be' embodied differently across these institutions. Admittedly, not to be overlooked in tending to differences across these two institutions are their similarities. In stewarding their collections, museums must privilege visual perception in aesthetic encounters, even if it is true that the ways visitors are encouraged, or expected, 'to see' art and nature vary. At the CBG, compared to the Met, there may be more spaces encouraging touch among more visitors, but these are outnumbered by those display gardens that do not explicitly do so.

As Kevin Hetherington $(2000,2002)$ has shown in his work on art museum programmes for the blind, limiting opportunities for touch in museums to the experiences of this group only enforces their 'otherness', while making plain the spatial politics of the museum environment. Notably, however, my analysis sheds light on efforts by museum professionals to consider the unique role touch and other forms of sensory interactions in museum can play for all visitors. As experts in crafting object-based perceptions, museum staff work within particular constraints, but my findings indicate this can beget innovation as much as it create limits. Studying how aesthetic experience is made (and remade) reveals that while museums frame conversations about difference, they can also potentially reframe them (Sandell 2007). As I argue here, these conversations can include the sensorial hierarchies we maintain when facilitating aesthetic experience. For those working in museums, this suggests a reconceptualization of aesthetics not simply as locally-determined but also explicitly embodied. Given the centrality of perception to museum practice, sociologists might do more to think about the role of the body in understanding aesthetic judgments.

Received March $2^{\text {nd }} 2015$

Finally accepted September $3^{\text {rd }} 2015$

\section{Acknowledgments}

This research was generously supported by an American Fellowship from the American Association of University Women. For their comments and advice throughout the writing process, the author thanks Wendy Griswold, Steve Epstein, Terry McDonnell, and the editors and three anonymous reviewers for Museum \& Society. Additional thanks go to those at The Metropolitan Museum of Art and Chicago Botanic Garden who participated in this research.

\section{Notes}

Both the International Council of Museums (ICOM) and the American Alliance of Museums (AAM), the largest professional organizations representing museums and museum professionals, include among their current ranks a diverse range of institutions including art museums, aquariums, arboreta, botanical gardens, children's museums, planetariums, science and technology centres, and zoos. For an early and influential taxonomy of American museums also including art museums and botanical gardens, see Goode (1896). American Alliance of Museums (AAM) 'Code of Ethics for Museums', 2000. http://www. aam-us.org/resources/ethics-standards-and-best-practices/code-of-ethics, accessed 12 
February 2015. International Council of Museums (ICOM) 'Development of the Museum Definition according to ICOM Statutes (2007-1946)', 2009. http://archives.icom.museum/ hist def eng.html, accessed 12 February 2015.

2 As Classen and Howes (2006: 207-208; see also Classen 2005; Howes 2014: 259-261), among others, have shown, the 'look, don't touch' rule in museums has changed over time. Growing public access to museums and changing ideas about 'proper' (visual) aesthetic appreciation interfaced with a variety of factors in the modernizing West to ultimately create by the mid-nineteenth century 'The Museum of Sight' we now take for granted as given.

3 For a comprehensive treatment of debates around the disunity of science, see Galison and Stump (1996). For discussion of the practice turn in contemporary theory and in science and technology studies, see Schatzki et al. (2001) and Pickering (1992), respectively.

4 As Wolff ([1983] 1993) has argued, sociologists tend to bracket both the specificity of art and autonomy of art objects in theories of aesthetics. This longstanding challenge to sociologists of art resonates with broader research suggesting cultural sociologists would benefit considerably from increased attention to materiality (Domínguez Rubio 2014; Griswold et al. 2013; McDonnell 2010; Mukerji 1994), defined as how objects and environments act upon people to influence action in ways that cannot be reduced to cognitive representations (Mukerji 1997). See Benzecry (2015) for a helpful recent parsing of literatures on aesthetics and materiality.

5 My use of 'sensory conventions' draws on economic theories of conventions as shared templates for interpreting situations and structuring action (Biggart and Beamish 2003), but also on cultural and organizational studies of conventions in sociology, particularly Becker's ([1982] 2008) notion of art as the product of collective action and his view of culture as negotiated through interactions organized by conventions.

6 A recent United States Census Report examining people with disabilities in America included communicative disabilities (people who are blind, or have difficulty seeing; deaf, or have difficulty hearing; difficulties with speech); mental disabilities (among them learning, intellectual, and developmental disabilities, or some form of dementia); and physical disabilities. Brault, M.W. 'Americans with Disabilities: 2010', United States Census Bureau 2012. http://www.census.gov/prod/2012pubs/p70-131.pdf, accessed 12 February 2015. 'Disability' is a notoriously slippery category, and as a label has tended to focus on the functional limitations of individual bodies rather than on how particular social contexts reproduce differences among embodied capacities (see Williams 2001). Rather than restricting inclusion criteria to administrative definitions, staff across the Met and CBG leading programs for visitors with disabilities offered programmes to any visitors who requested accommodations.

7 Rather than a singular 'masterpiece,' the 'collection' unit in botanical gardens is more likely to consist of an entire species of plants. As one CBG curator told me (see n. 12), plants are typically seeded and growing in different museums across geographic areas. As he went on to explain, in the unlikely scenario that 'half of the US is wiped out,' botanic gardens can function as a safeguard against the loss of entire plant species. In some contrast, he added: 'No one is going to propagate the Mona Lisa'.

8 Personal communication with staff member, 30 January 2015.

9 The idea of the behaviour setting helpfully connects cultural sociologists' conception of 'object settings' (McDonnell 2010; see also Klett 2014) with the literature on organizational identity evaluating how organizational forms shape, and are shaped by, particular organizational practices and goals (see Whetten 2006 for a review).

10 Personal communication, 24 July 2014. 
11 Interview by author, detailed notes taken upon subject's request, 24 March 2014.

12 All referenced communications with curator are from an interview by the author, digital recording, 20 March 2014.

13 Interview by author, digital recording, 10 December 2012.

14 In a later conversation, Harriet, responding to my observation that she often guided attention to the objects by soliciting participants' opinions, stated: 'Well, that's basic Rika Burnham', referencing a well-known publication discussing varying approaches toward incorporating visitors' observations in art museum teaching (Burnham and Kai-Kee 2011). Personal communication, 5 June 2014.

15 Interview by author, digital recording, 3 August 2010.

16 Interview by author, detailed notes taken upon subject's request, 4 December 2014.

17 Pierre Bourdieu (1984) has shown the shared experience of a 'pure gaze' Kant associates with the experience of art actually reinforces a boundary between those who have through their upbringing been tutored to appreciate art from those who do not have such cultural capital. As Bennett (1998; see also [2006] 2011) has argued, many of the efforts to translate aesthetic experiences through educational resources - successful or otherwise - have been an attempt by museums to 'speak to all eyes'.

18 Interviews both by author, digital recordings, 8 April 2014 and 4 June 2014 respectively.

19 See pages 60-1 of Reedy, J.P. (ed). 1990. It's Fun To Remember, Book II: A Story about the Women's Board of the Chicago Horticultural Society and Other Kindred Events 1975 - July 1990, Chicago Horticultural Society archives: managed by the Lenhardt Library of the Chicago Botanic Garden.

20 Follow-up interview by author, digital recording, 14 August 2013.

21 Winn, Robert (Dr.), Hadley School for the Blind. 'Botanic Garden Committee Meeting on November 21, 1985'. Chicago Horticultural Society archives, managed by the Lenhardt Library of the Chicago Botanic Garden. Box 51B, folder 11.

22 Interview by author, digital recording, 30 May 2014.

23 Interview by author, digital recording, 24 October 2014.

\section{References}

Becker, H.S. ([1982] 2008) Art Worlds, Berkeley: University of California Press.

Benzecry, C. E. (2015) 'Restabilizing Attachment to Cultural Objects: Aesthetics, Emotions and Biography', The British Journal of Sociology, 66 (4) 779-800.

Bennett, T. (1998) 'Speaking to the Eyes: Museums, Legibility, and the Social Order', in Sharon MacDonald (ed.) The Politics of Display: Museums, Science, Culture, 22-30, London: Routledge.

Bennett, T. ([2006] 2011) 'Civic Seeing: Museums and the Organization of Vision', in Sharon MacDonald (ed) A Companion to Museum Studies, 263-81, Oxford: Blackwell.

Biggart, N.W. and T. D. Beamish. (2003) 'The Economic Sociology of Conventions: Habit, custom, practice, and routine', Annual Review of Sociology 29: 443-64 
Bourdieu, P. (1984) Distinction: A Social Critique of the Judgment of Taste, Cambridge: Harvard University Press.

Bourdieu, P. and Darbel, A. ([1969] 1991) The Love of Art: European Art Museums and Their Public, Cambridge: Polity Press.

Burnham, R. and Kai-Kee, E. (2011) Teaching in the Art Museum: Interpretation as Experience, Los Angeles: Getty Publications.

Classen, C. (2005) 'Touch in the Museum', in Constance Classen (ed.), The Book of Touch, 228-39, Oxford: Berg.

Classen, C. and Howes, D. (2006) 'The Museum as Sensescape: Western Sensibilities and Indigenous Artefacts', in E. Edwards, C. Gosden and R. B. Phillips (eds) Sensible Objects: Colonialism, Museums and Material Culture, 199-222, Oxford: Berg.

DiMaggio, P.J. and Powell, W.W. (1983) 'The Iron Cage Revisited: Institutional Isomorphism and Collective Rationality in Organizational Fields', American Sociological Review 48 (2) $147-60$.

Domínguez Rubio, F. (2014) 'Preserving the Unpreservable: Docile and Unruly Objects at MoMA', Theory and Society, 43 (6) 617-45.

Driscoll, R. (2011) 'Aesthetic Touch', in F. Bacci and D. Melcher (eds) Art and the Senses, 107-14, Oxford: Oxford University Press.

Falk, J.H. and Dierking, L.D. (2000) Learning from Museums: Visitor Experiences and the Making of Meaning, Lanham: AltaMira Press.

Fyfe, G. (2006) 'Sociology and Social Aspects of Museums' in Sharon MacDonald (ed.) A Companion to Museum Studies 33-49, Oxford: Blackwell.

Galison, P. and Stump, D.J. (eds) (1996) The Disunity of Science: Boundaries, Contexts, and Power, Stanford: Stanford University Press.

Gieryn, T.F. (2000) 'A Space for Place in Sociology', Annual Review of Sociology (26) 46396.

Glaser, B.G. and Strauss, A.L. (1967) The Discovery of Grounded Theory: Strategies for Qualitative Research, Chicago: Aldine Publishing Company.

Goode, G. B. (1896) 'On the Classification of Museums', Science, 3 (57) 154-61.

Griswold, W., Mangione, G., and McDonnell, T. E. (2013) 'Objects, Words, and Bodies in Space: Bringing Materiality into Cultural Analysis', Qualitative Sociology 36 (4) 34364.

Hallett, T. and Ventresca, M. (2006) 'Inhabited institutions: Social interaction and organizational forms in Gouldner's patterns of industrial bureaucracy', Theory and Society (35) 213-36.

Hetherington, K. (2000) 'Museums and the Partially-sighted: the Spatial Politics of Access', The Sociological Review 48 (3) 444-63.

Hetherington, K. (2002) 'The Unsightly: Visual Impairment, Touch and the Parthenon Frieze', Theory, Culture and Society, 19 (5-6) 187-205.

Howes, D. (2014) 'Introduction to Sensory Museology', The Senses and Society 9 (3) 25967. 
Kant, I. (1998) Critique of Pure Reason, P. Guyer and A.W. Wood (eds) Cambridge: Cambridge University Press.

Klett, J. (2014) 'Sound on Sound: Situating Interaction in Sonic Object Settings', Sociological Theory 32 (2) 147-61.

Knorr-Cetina, K.D. (1981) The Manufacture of Knowledge: An Essay on the Constructivist and Contextual Nature of Science, Oxford: Pergamon Press.

Knorr-Cetina, K.D. (1983) 'The Ethnographic Study of Scientific Work: Towards a Constructivist Interpretation of Science', in K.D. Knorr-Cetina and M. Mulkay (eds) Science Observed: Perspectives on the Social Study of Science, 115-30, Beverly Hills: Sage.

Knorr Cetina, K. (1999) Epistemic Cultures: How the Sciences Make Knowledge, Cambridge: Harvard University Press.

Latour, B. and Woolgar, S. ([1979] 1986) Laboratory Life: The Construction of Scientific Facts, Princeton: Princeton University Press.

Levent, N. and Pascual-Leone, A. (eds) (2014) The Multisensory Museum: CrossDisciplinary Perspectives on Touch, Sound, Smell, Memory, and Space, Lanham: Rowman \& Littlefield.

Lynch, M. (1985) Art and Artifact in Laboratory Science: A Study of Shop Work and Shop Talk in a Research Laboratory, London: Routledge and Kegan Paul.

Mangione, G. (2013) 'Access to What?: Alzheimer's Disease and Esthetic Sense-Making in the Contemporary Art Museum', Poetics 41 (1) 27-47.

McDonnell, T. E. (2010) 'Cultural Objects as Objects: Materiality, Urban Space, and the Interpretation of AIDS Campaigns in Accra, Ghana', The American Journal of Sociology, 115 (6) 1800-52.

Mukerji, C. (1994) 'Toward a Sociology of Material Culture: Science Studies, Cultural Studies and the Meanings of Things', in Diana Crane (ed.) The Sociology of Culture: Emerging Theoretical Perspectives, 143-62, Cambridge: Blackwell.

Mukerji, C. (1997) Territorial Ambitions and the Gardens of Versailles, Cambridge: Cambridge University Press.

Pickering, A. (1992) Science as Practice and Culture, Chicago: University of Chicago Press.

Powell, W.W. and DiMaggio, P.J. (1991) 'Introduction', in P.J. DiMaggio and W. W. Powell (eds) The New Institutionalism in Organizational Analysis, 183-203, Chicago: University of Chicago Press.

Rowland, N. and Rojas, F. (2006) 'Bringing Technology Back In: A Critique of the Institutionalist Analysis of Museums', Museum \& Society, 4 (2) 84-95

Sandell, R. (2007) Museums, Prejudice and the Reframing of Difference, London: Routledge.

Schatzki, T.R., Knorr Cetina, K., and von Savigny, E. (eds) (2001) The Practice Turn in Contemporary Theory, London: Routledge.

Vannini, P., Waskul, D. and Gattschalk, S. (eds) (2012) The Senses in Self, Society, and Culture: A Sociology of the Senses, New York: Routledge. 
Whetten, D.A. (2006) 'Albert and Whetten Revisited: Strengthening the Concept of Organizational Identity', Journal of Management Inquiry 15 (3) 219-34.

Whitley, R.D. (1970) 'Black Boxism and the Sociology of Science: A Discussion of the Major Developments in the Field', The Sociological Review 18 (1) 61-92.

Williams, G. (2001) 'Theorizing Disability', in G.L. Albrecht, K.D. Seelman, M. Bury (eds) Handbook of Disability Studies, 123-44, Thousand Oaks: Sage.

Wolff, J. ([1983] 1993) Aesthetics and the Sociology of Art, Ann Arbor: University of Michigan Press.

Zolberg, V.L. (1992) 'Barrier or Leveler? The Case of the Art Museum', in M. Lamont and M. Fournier (eds) Cultivating Differences: Symbolic Boundaries and the Making of Inequality, 187-209, Chicago: University of Chicago Press.

*Gemma Mangione is a doctoral candidate in sociology at Northwestern University with research interests in culture, health, knowledge, and organizations. Her dissertation examines how art museums and botanical gardens organize and innovate programmes for visitors with disabilities. Her research on museums has appeared in Poetics and Qualitative Sociology.

\section{Address:}

Northwestern University

Department of Sociology

1810 Chicago Avenue

Evanston, IL 60208

USA

E-mail: gmmangione@u.northwestern.edu 